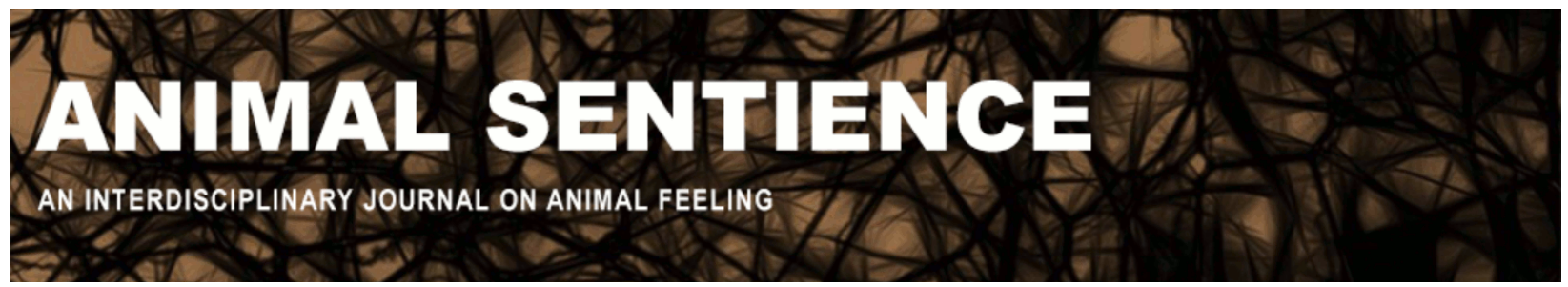

Monsó, Susana (2019) Humans are superior - by human standards. Animal Sentience 23(17)

DOI: $10.51291 / 2377-7478.1389$

Date of submission: 2019-01-29

Date of acceptance: 2019-02-15 (c) 


\title{
Humans are superior - by human standards
}

Commentary on Chapman \& Huffman on Human Difference

\author{
Susana Monsó \\ Messerli Research Institute \\ University of Veterinary Medicine Vienna
}

\begin{abstract}
Chapman \& Huffman argue that humans are neither unique nor superior to other animals. I believe they are right in claiming that we are no more unique than any other species, but wrong in assuming that this means we cannot be ranked as superior. I show how this need not undermine the central aim of their target article, for superiority can only be measured with respect to a certain standard, and it's only by using anthropocentric standards that we can be plausibly regarded as superior. Other - perhaps more neutral — standards yield different results.
\end{abstract}

Susana Monsó is a post-doctoral research fellow at the Unit of Ethics and Human-Animal Studies of the Messerli Research Institute in Vienna. She works in philosophy of animal minds and animal ethics. Website

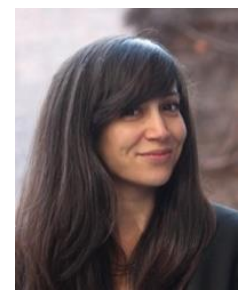

Chapman \& Huffman (2018) (C \& H) argue against the widespread conception of humans as unique and superior to nonhuman animals (hereafter "animals"). They start off by pointing out that all attempts to ground human uniqueness in a specific capacity have failed, since all the capacities that typically characterize humans can be found, to a greater or lesser extent, in other species. They further argue that the very idea of humans as "one of a kind, unlike anything else" contradicts evolutionary theory, which predicts that there will be a continuity in the characteristics found across the animal kingdom. Last, they argue that the differences that can be identified among species "are value-free and of interest because they provide diversity" and that "since all traits cannot be taken into account simultaneously, it is inappropriate to accord superiority to a subset of traits that are preselected in a biased or ad-hoc fashion." This, in C \& H's view, ultimately means that it is unwarranted for us to consider ourselves superior to other species, and to use this purported superiority to justify placing our own interests ahead of those of the animals we share a planet with.

I agree with the overall spirit of the target article, but would like to argue that reflecting upon which species are superior to which need not be an arbitrary endeavor, and that doing so may even help the cause for which $\mathrm{C} \& \mathrm{H}$ are advocating.

To begin with, one should note that "superiority" is not in itself a trait that is intrinsically present in any species. Instead, it is a trait that can be attributed to a species in comparison to another species, but also, and crucially, with respect to a certain standard. It thus does not make sense to say that humans are superior to other species tout court. The most we can say is that humans are superior in some particular sense or by a certain standard. And there are certainly standards by which we are superior to other species. Take, for instance, the case of language. It's 
not very fair to say that, when it comes to linguistic abilities, the differences found across Earth's species are "value-free," to use C \& H's terminology. In fact, it is entirely possible to rank different species with respect to their linguistic or communicative abilities, taking as a yardstick, for example, the complexity of the information they can convey, or the range of ideas they can express. Humans would, without a doubt, come first in this ranking. But this is not as important as the fact that this is an entirely expected result, because we are using a human-typical characteristic as our standard. If we were to rank species with respect to their ability to echolocate, then bats or dolphins might come first. The thought of using language as the yardstick might seem as absurd to bats and dolphins as the thought of using echolocation is to us.

$\mathrm{C} \& \mathrm{H}$ may have been hinting at this idea when they say that the selection of traits on which to measure superiority is always going to be either "biased or ad hoc." But isn't there any standard that we can use that counts as neutral? Must results be necessarily biased in favor of one species or another? I would like to suggest that, even though full neutrality might be difficult to achieve, there are traits that are plausibly constructed as valuable across all species, and which can be used to rank them in a way that is neither biased nor ad hoc.

One such candidate might be the survival capacity of individuals. Survival seems to be something that individuals of all species strive for, at least during a significant proportion of their lives. Thus, we can ask, are individuals of the human species superior to individuals of other species in their survival capacity? Our superiority is in this case far from clear. Though our smarts certainly give us an advantage in some threatening situations, our survival capacity pales when compared, for instance, to that of tardigrades. These microanimals can survive without food or water for up to thirty years. They are able to withstand temperatures close to absolute zero and up to $150^{\circ} \mathrm{C}$, as well as pressures 1,200 times greater than that of the atmosphere. They can take hundreds of times the radiation that would kill us and can even survive for several days in the vacuum in outer space (see Møbjerg et al. 2011). It seems fair to say that tardigrades are superior to us when it comes to their survival capacity.

One might counterargue by saying that although humans don't have such high survival capacity as individuals, we are nevertheless superior when it comes to the survival ability of our species as a whole, since we are hyper-cooperative animals that are strongest as a group. But even if we were to take species survival capacity as our standard, we'd have difficulties arguing for our superiority. Jellyfish, for instance, have been around for at least 500 million years, having managed to survive the five mass extinctions that have taken place in the history of Earth (Cartwright et al. 2007). It is doubtful that humans will make it that far. We have existed for barely 200,000 years and are already well on the way to creating the perfect conditions for our own species to become extinct.

These are just some suggestions of how we might go about ranking species in a more "neutral" way. The conclusion I want to stress is that there is some value to engaging in a critical reflection on the topic of species superiority, especially for the sort of debate that $\mathrm{C} \& \mathrm{H}$ want to trigger. A comparison to other species using fairer standards can help humans realize that we are not as special as we like to think we are. It can be a humbling experience, one that can ultimately raise awareness of the unjustifiability of living on this planet as if it were only ours. 


\section{References}

Cartwright, P., Halgedahl, S. L., Hendricks, J. R., Jarrard, R. D., Marques, A. C., Collins, A. G., \& Lieberman, B. S. (2007). Exceptionally preserved jellyfishes from the Middle Cambrian. PLOS ONE, 2(10), e1121.

Chapman, C. A., \& Huffman, M. A. (2018). Why do we want to think humans are different? Animal Sentience 23(1).

Møbjerg, N., Halberg, K. A., Jørgensen, A., Persson, D., Bjørn, M., Ramløv, H., \& Kristensen, R. M. (2011). Survival in extreme environments - on the current knowledge of adaptations in tardigrades. Acta Physiologica, 202(3), 409-420. 